\title{
¿Una revolución cultural? Reflexiones sobre la década de los sesenta en la República Federal Alemana'
}

\author{
RoBERT P. STEPHENS \\ Virginia Polytechnic, USA
}

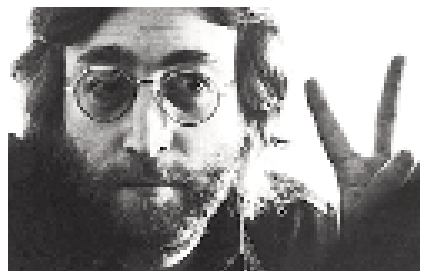

\author{
"Es cierto que ahora hay mucha gente que anda por ahi \\ con el pelo largo y unos cuantos chicos de clase media \\ que van vestidos a la moda. Pero nada ha cambiado \\ a excepción de que todos nos vestimos un poco mejor \\ $y$ dejamos que los mismos canallas lo dirijan todo.» \\ JoHN LENNON, I97I
}

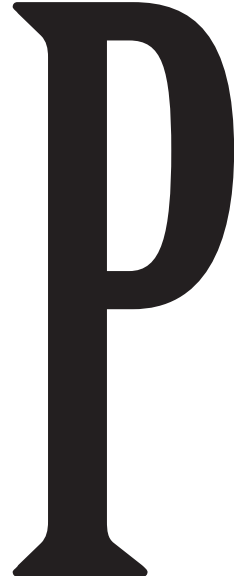

uede parecer un cliché comenzar con esta omnipresente cita de John Lennon extraída de su entrevista para la revista británica The Red Mole en 1971. Y bien es cierto que ya ha sido utilizada para toda clase de propósitos a lo largo de los años: para difamar los esfuerzos de los partidarios de la Revolución Cultural del 68, para justificar una crítica conservadora al libertinaje de los años sesenta o, a menudo, en un intento vehemente por descubrir a los «Working Class Heroes» («Héroes de la Clase Obrera»). Pero, al igual que tantos otros, opino que las palabras de Lennon se ajustan bien a mis propósitos. Por medio de este artículo, me gustaría reflexionar sobre una serie de debates acerca de la trascendencia de los sesenta. En concreto, pretendo compartir cómo ha evolucionado mi forma de concebir la noción de «revolución cultural» y la relación entre comercio y cultura durante lo que se conoce como «los largos años sesenta».

Gran parte de este debate debe su origen a la obra The Sixties de Arthur Marwick publicada en 1999, la cual ha enmarcado a su vez muchos de los debates más recientes sobre esta década tan crucial. Esta controvertida obra resultó emocionante al mismo tiempo que exasperante para los lectores de la época, entre los que me incluyo (Passerini 1999; Willis 1998). Me gustaría centrarme particularmente en dos de las reivindicaciones más significativas de este autor. En primer lugar, Marwick sostiene que entre 1958 y 1967 tuvo lugar una «revolución cultural» que transformó «las condiciones materiales, el estilo de vida, las relaciones familiares y las libertades personales de gran parte de la gente corriente» (Schildt y Siegfried 2006: 39-58). Marwick continúa aclarando que «definitivamente no hubo una revolución política o económica, así como tampoco hubo una redistribución fundamental del poder político y económico» (1999: 15). En segundo lugar, también insiste, de forma un tanto provocadora, en que la mayoría de los movimientos

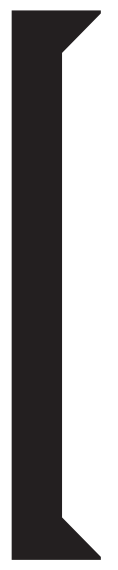

Desde mi punto de vista, resulta evidente

que algo sucedió, pero la verdadera cuestión

reside en cómo describirlo.

Para ello convendría aclarar qué se entiende fundamentalmentepor revolución cultural.

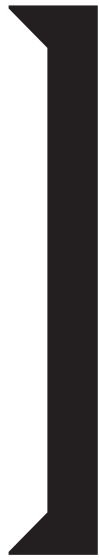

sociales y subculturas de los años sesenta «se vieron completamente afectados por una ética empresarial, orientada hacia fines lucrativos» (1999: 13). Marwick se esfuerza enormemente por justificar su rechazo hacia toda idea de revolución de tendencia marxista, por vaga que sea, e insiste en que durante los años sesenta nunca hubo cabida para una revolución política y económica. Según explica, en lugar de esto se produjo una transformación general de la cultura en todas sus vertientes como resultado de la combinación de las proliferantes revoluciones de la vida cotidiana. En la versión de Marwick de los años sesenta, tanto los marxistas, liderados sin un rumbo claro, como los descontrolados grupos contraculturales, llevaron a la poderosa élite política liberal a realizar concesiones razonables (él acuña la expresión «juicio comedido» para describir este trato considerado), de manera que a finales de los «largos años sesenta», estos cambios habían consolidado una genuina e inexorable transformación.

Empezaré abordando el concepto de revolución cultural y continuaré con algunas reflexiones acerca de la noción de periodización. Desde mi punto de vista, resulta evidente que algo sucedió, pero la verdadera cuestión reside en cómo descri- 


\section{Resumen}

Por medio de este artículo, me gustaría reflexionar sobre una serie de debates acerca de la trascendencia de los sesenta. En concreto, pretendo compartir cómo ha evolucionado mi forma de concebir la noción de «revolución cultural» y la relación entre comercio y cultura durante lo que se conoce como «los largos años sesenta». En mi opinión, el problema de la interpretación liberal y apolítica de la década de los sesenta guarda relación con la sustitución de las corrientes historiográficas más radicales a lo largo de la última década por un triunfalismo infundado que ha ocupado una posición central en la historiografía desde la caída de la Unión Soviética.

Schlüsselwörter: Alemania, revolución cultural, años sesenta, industria cultural, drogas

\section{Abstract}

In this article, I would like to take the opportunity to reflect on a set of debates about the import of the sixties. In particular, I would like to share the evolution of my thinking about the notion of a "cultural revolution" and the relationship between commerce and culture over the "Iong sixties." My problem with this liberal reading of the sixties has to do with the abandonment of radical historiography over the past decade, and its replacement with a Panglossian triumphalism that has taken historiographic center stage since the collapse of the Soviet Union.

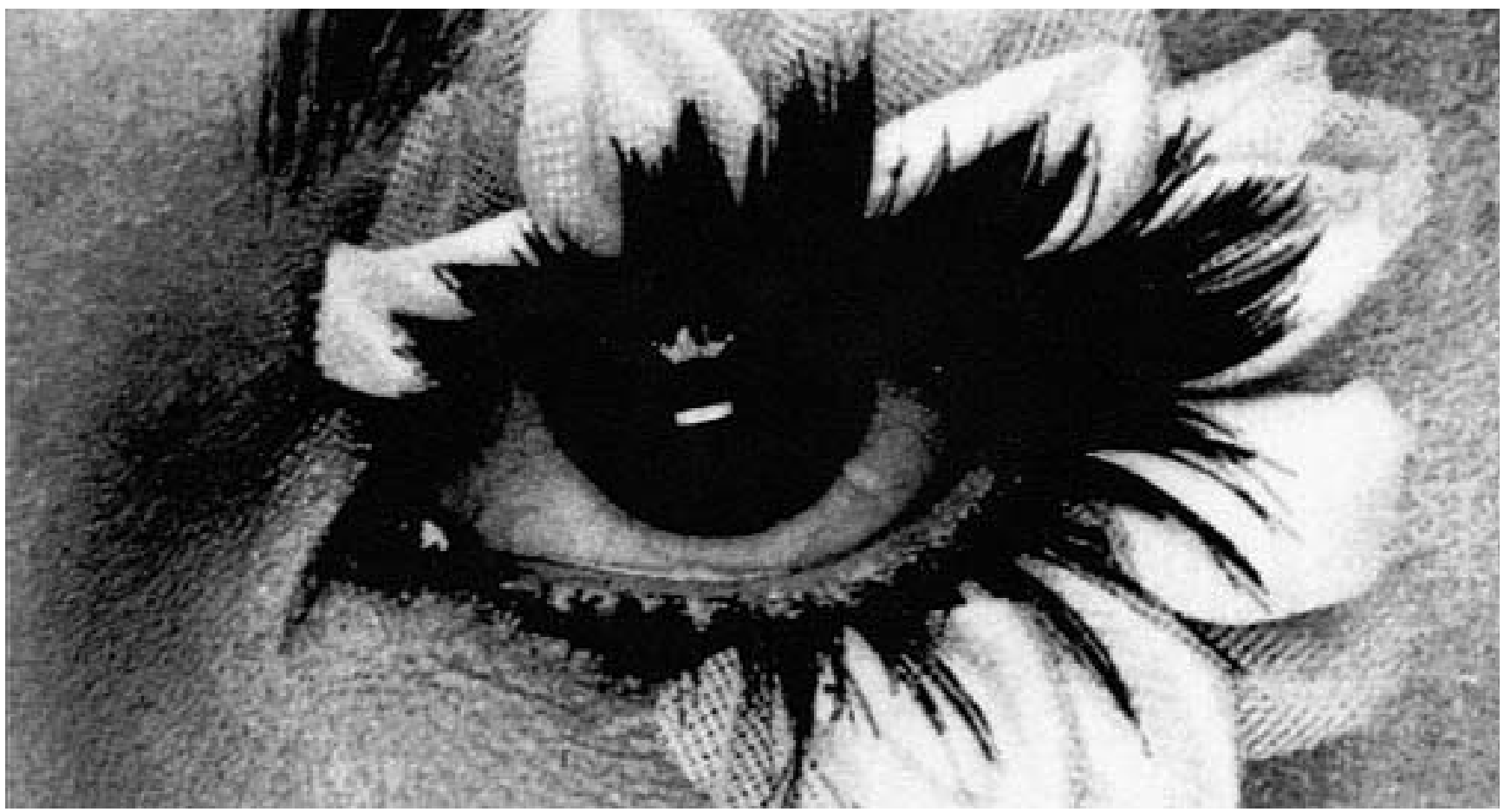

birlo. Para ello convendría aclarar qué se entiende fundamentalmente por revolución cultural. Aunque, al igual que Marwick, opino que esencialmente se produjeron cambios profundos en la vida cotidiana de los individuos, estoy seguro de que tanto estos individuos como los grupos que formaban parte de movimientos estudiantiles y contraculturales consideraban que su labor iba más allá de las meras transformaciones en la vida cotidiana. Esto es, que cuando muchos de ellos la gran mayoría se describían a sí mismos como revolucionarios, verdaderamente lo creían (Schildt y Siegfried 2006; Koenen 2001 y 2003). Los estudiantes de Europa Occidental, tal y como Philipp Gassert y Martin Klimke afirman, "pronto se imaginaron a sí mismos formando parte de una lucha a escala global contra la explotación capitalista y la represión comunista, contra el régimen colonial y el dominio imperialista» (2009:5). A pesar de que las ideas revolucionarias en el ámbito político, económico y social se yuxtaponían y convergían en numerosos aspectos, la mayoría de los autores contemporáneos, muchos de los cuales coincidían en poco más, parecen estar de acuerdo en que la «juventud» formó parte de un proyecto revolucionario, aunque formulado de manera imprecisa. 
do de la pornografía, corrupción de menores, desinhibición sexual, retrasos en los medios de transporte, corrupción, depravación, drogas, fracaso de nuestras instituciones de enseñanza, deterioro del idioma (especialmente, a través del uso de terminología que hace alusión a los órganos genitales y a la defecación), las conocidas como "generaciones bisagra», antisemitismo, incapacidad y pasividad de los partidos políticos (2002: 321; v.tb. Aly 2008)2

Estas tres interpretaciones me dejan indiferente, quizás porque se han utilizado como armas de confrontación en demasiadas ocasiones durante el prolongado conflicto cultural de la década de los sesenta.

Más interesante me resulta el persistente interés por el consumo y por el papel que este ha desempeñado durante la larga década de los sesenta. En este sentido, Detlef Siegfried (2006) ha abordado el nexo entre política y consumo de forma exhaustiva y con mucha más precisión de la que yo podría hacerle justicia aquí. Por este motivo, en su lugar me centraré en una serie de cuestiones que, aun siendo distintas, tienen que ver con las relaciones que se establecen entre cultura, consumo y comercio: ¿qué función desempeñó el comercio en el proceso de cambios que tuvo lugar durante la década de los sesenta? $¿$ No resulta paradójico que por un lado se fomente y por otro lado se rechace el consumo, o mejor dicho, la ideología y la praxis del consumo?

El debate sobre la relación entre el mercado y los cambios a largo plazo en los sistemas de valores (Wertewandel) tiene una larga y prestigiosa historia (Siegfried 2006; Renner 1968: 8587). Tal y como Detlef Siegfried señala, muchos están de acuerdo en que un cambio fundamental en la estructura del sistema de valores trajo consigo, de forma asíncrona y desigual, la expansión de la cultura del consumo, el desarrollo de los medios de comunicación de masas y el auge del sector servicios. Por su parte, el enorme incremento del poder adquisitivo y del tiempo libre despertó en la sociedad cierta sensibilidad «postindustrial» a mediados de los setenta (2006: 51-59). Sin embargo, en lo que a la historiografía alemana occidental respec- ta, aún no queda completamente claro cómo o por qué ocurrió este cambio o, dicho de otro modo, aún no se ha establecido la ponderación relativa de las distintas causas implicadas (Siegfried 2006: 51-59). Asimismo, creo que no se ha llegado a un consenso respecto al papel que tuvieron el sexo, las drogas y el rock and roll en estos cambios fundamentales del sistema de valores. En otras palabras, ¿ejercieron estos tres elementos algún tipo de influencia, o fueron meras consecuencias de los cambios en los mecanismos del capitalismo?

Llegamos así al quid de la cuestión. Tras reflexionar al respecto, he llegado a una conclusión bastante pesimista: la tesis de Marwick sobre una revolución cultural sigue sin convencerme por completo. Mi objeción a describir los cambios de los largos años sesenta como «revolucionarios» se basa principalmente en dos fundamentos.

El primero de ellos es de carácter político. William Fine y Nancy Love consideran que la postura de Marwick es propia de los «liberales progresistas», quienes comparten un mismo criterio del cambio evolutivo que desencadenaron los años sesenta y rechazan las interpretaciones más radicales por considerarlas absurdas. Particularmente, se oponen a las interpretaciones de tendencia marxista, aunque en este sentido Marwick acuñaría el término de origen francés «marxisant», con el que se describe todo aquello que se ve influenciado o es cercano al marxismo. Por su parte, Marwick sugiere que «la ciencia histórica defiende un estado de bienestar apoyado en el liberalismo» (1999: 295). En Alemania, Konrad Jarausch respaldó, de forma más contundente, un argumento similar que contempla la década de los sesenta como la clave para un "proceso de civilización» que tuvo lugar en el periodo de la posguerra, durante el cual «el efecto conjunto de la rebelión generacional, la victoria en las elecciones a favor de la coalición social-demócrata y otros cambios en los valores de la sociedad proporcionaron un impulso adicional a favor de la liberación de la sociedad alemana occidental» (Jarausch 2006: 17).

En mi opinión, el problema de esta forma de interpretar la década de los sesenta guarda relación con la sustitución de las cor-
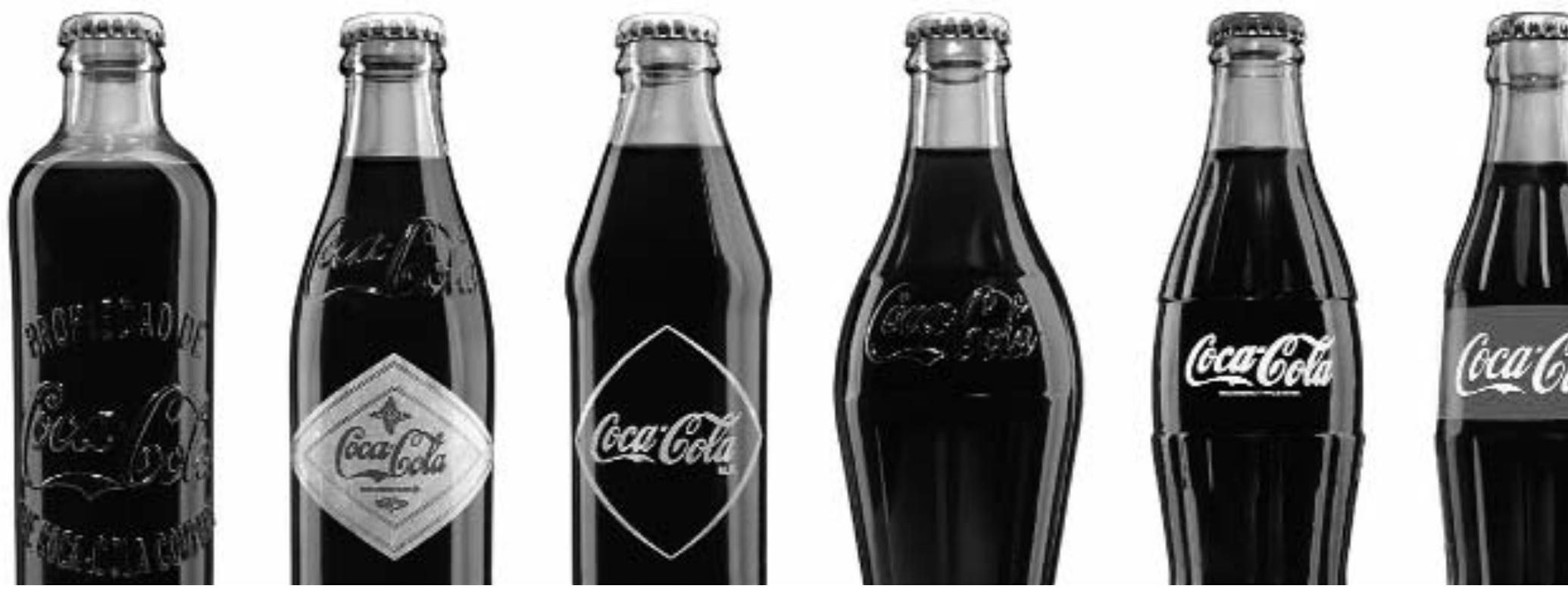
rientes historiográficas más radicales a lo largo de la última década por un triunfalismo infundado que ha ocupado una posición central en la historiografía desde la caída de la Unión Soviética. Puesto que, tanto el «centralismo democrático» como el «socialismo de estado» han fracasado, puede decirse que vivimos en un mundo mejor. Esta aceptación del consumo posmoderno y del sistema democrático liberal y parlamentario como opción definitiva desde una perspectiva histórica me parece de lo más alarmante. Sigo convencido de que Warren Susman (1984) estaba en lo cierto cuando recalcaba el hecho de que, junto con las visiones más progresistas e incluso utópicas de una sociedad más justa, las investigaciones de los historiadores desempeñan un papel crucial a nivel social e intelectual. Por ello, creo que las reiteradas peticiones de un cambio en la sociedad que se produjeron durante los años sesenta son imprescindibles para poder explicar e interpretar esta década, a pesar de que Marwick opte por dejarlas al margen y Jarausch las considere insuficientes, aunque bien es cierto que reconoce su importancia.

El segundo de mis motivos no es de carácter político, sino que se apoya en un argumento sustancial y guarda estrecha relación con la ingente cantidad de estudios sobre el consumis-

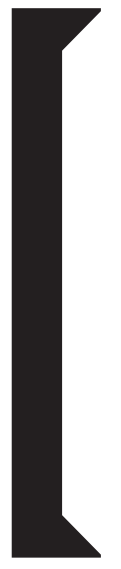

Ell gusto en la música, las drogas,

las preferencias sexuales y las conductas

acumularon tanto capital cultural que

terminaron por crear distinciones sociales.

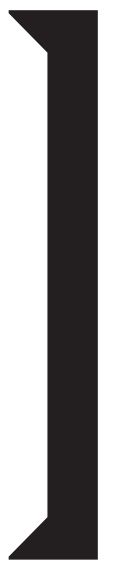

mo y la sociedad de consumo que se han realizado a lo largo de las dos últimas décadas. Estos estudios suelen situar los «orígenes» del consumismo cada vez más alejados en el tiempo. «Durante la segunda mitad del siglo XIX, la revolución en el consumo fue tomando forma hasta que terminó por consolidarse durante la segunda mitad del siglo XX» (Jarausch y Geyer 2003: 275). Tal y como ellos señalan, este longue durée (largo periodo) estuvo plagado de irregularidades y salpicado de catástrofes y fracasos. Incluso la organización de los medios de distribución y la metodología del consumo, así como los patrones en la forma de gastar y comprar, parecen mostrar una significativa continuidad desde el imperio alemán hasta la actual república federal (Swett et al. 2007; Grazia 2005; Crew 2003; Strasser et al. 1998). También aquellos productos que, a nuestro parecer, comenzaron a producirse y a comercializarse a raíz de la década de los sesenta, como es el caso de los productos sexuales, se remontan en realidad a una época mucho anterior a la revolución sexual, tal y como Elisabeth Heineman (2006 y 2011) ha demostrado.
De manera que en lugar de ver los «largos años sesenta» (que empezaron con un auge del consumo en 1958-1959) como una revolución, diría que deben ser considerados la «Gran Aceleración». Dado que los años sesenta están enmarcados por un boom económico por una parte y por un colapso económico por la otra, podríamos establecer que abarcan principalmente la era del auge en el consumismo de la «Edad de Oro» (Hobsbawn 2001). Debemos estudiar esto como una aceleración e intensificación de unos modelos económicos y culturales que ya existían en lugar de analizarlo como algo completamente novedoso. En última instancia, el capitalismo se nutrió del aumento de los salarios, el gasto de los consumidores y en el caso de Alemania Occidental, las continuadas exportaciones de bienes duraderos.

¿Y qué cambió? Un conflicto a largo plazo entre determinados valores sociales y culturales varió decisivamente a lo largo de los sesenta. La economía del placer sustituyó gradualmente a una economía del impuesto o el ahorro (Siegfried 2006, 5159). Aunque esto es claramente "cultural», el cambio no tiene sentido sin un nuevo mundo de cosas placenteras y la expansión de la economía formal e informal, que se reorganizaron para saciar los deseos de los consumidores. Pese a que hubo ciertas diferencias generacionales en este proceso, apenas hay dudas de que la transformación fue a la vez profunda y generalizada, aunque los objetos de deseo fueran diferentes. Lo que es significativo es que el consumismo y los cambios en los valores socioculturales estaban íntimamente unidos y se retroalimentaban en un ciclo de cambio.

Esta es la perspectiva general. Ahora bien, ¿cómo se relaciona esto con la juventud y, particularmente, con nuestro tema: sexo, droga y rock and roll? La cuestión de la autenticidad en este aspecto no es de mi interés. La autenticidad, al igual que el resto de tropos, tiene una historia (Rossinow 1998). Lo que quiero tratar es la importancia de un cambio en la forma en que la gente concebía los mercados en los cincuenta y el efecto de estos cambios en la ideología de la juventud en los sesenta y setenta.

La clave para esto es el derrumbamiento del mercado de masas y la aparición de la segmentación del mercado (Cohen 2003; Grazia 2005; Stephens 2007). Esta transformación en la manera en que los capitalistas y empresarios entendían el mercado permitió la aparición del capitalismo pop y, a principios de los sesenta, el fomento de determinados «estilos de vida». Los «estilos de vida", aunque parezcan auténticos y un verdadero reflejo del «yo» interior, eran ante todo un conjunto de objetos y atributos que representaban a los individuos en un ámbito social. Como Bourdieu señaló: «El gusto clasifica y clasifica a los clasificadores». (1984:6) Y aquí es donde aparecen el sexo, las drogas y el rock and roll. Combinados de varias formas se convirtieron en los símbolos de determinados «estilos de vida contraculturales», y he de remarcar que no había un estilo de vida contracultural rígido, sino una proliferación de estilos de vida diferentes y creadores de diferencias (Chaney 1996). El gusto en la música, las drogas, las preferencias sexuales y las conductas acumularon tanto capital cultural que terminaron por crear distinciones sociales. Esto no quiere decir que la gente joven no encontrara estas experiencias libera- 
doras, ni tampoco es un intento de negar que la contracultura creyera que esto era «real» y auténtico, sino que pretende señalar que incluso las partes del «estilo de vida» que eran explícitamente anti-consumistas fueron incorporadas a ese «estilo de vida» para volver a ser a empaquetadas, emitidas y vendidas. Creo firmemente en la idea de Thomas Frank (1997) de un «consumismo de moda, una especie de máquina cultural en constante movimiento en la que la indignación, que junto con la falsedad, la baja calidad y las opresiones cotidianas de la sociedad consumista, pudieran ser usadas para conducir las cada vez más aceleradas ruedas del consumo». Considero que puedo decir, sin temor a exagerar, que el mismo proceso ocurre en Alemania Occidental con un pequeño y decreciente desfase temporal.

Antes de que se me tache de hereje del determinismo económico, quiero redirigir el discurso hacia cómo reconceptualizar la economía de la contracultura para mitigar los efectos de mis argumentos legítimamente incriminatorios sobre el «estilo de vida». Los debates sobre el consumo, el poder y la resistencia ya han sido planteados en numerosas ocasiones. La variante primordial de este debate debe su origen a la Escuela de Frankfurt y a la cuestión del poder de la industria de la cultura (Adorno 2001). Bien es cierto que la mayoría de los historiadores responderían ahora a esta tesis con una aceptación de la flexibilidad de significado y el poder de los consumidores para hacer nuevas versiones de los productos culturales (Hebdige 1979; Cook 1996). Pero este debate tiende a crear una dicotomía difícil de superar entre el comercio de la industria cultural por una parte y el Eigen-Sinn de los consumidores en la otra (Siegfried 2006: 17-18; Lüdtke 1995; Richthofen 2009). Aunque ambos son indudablemente ciertos: la cultura de la industria creó, se apropió y difundió productos envueltos en estilo y los consumidores le otorgaron a estos productos sus propios significados. Sin embargo, este nexo artificial donde confluyen el comercio y el consumidor no explica completamente cómo se construyeron los "estilos de vida", particularmente los contraculturales.

Quisiera mencionar la existencia de una economía social «mediadora» o «informal» que a menudo mediaba entre los productos y los grupos sociales. En otras palabras, para conseguir el éxito debían tomarse decisiones sobre las elecciones y prácticas aceptables o inaceptables del consumidor. Estas elecciones no pueden ser individuales; necesitan la interacción social. Es decir: los grupos (que usualmente se formaban según la clase social) decidían qué era guay y había una circulación informal de ideas y cosas que determinaban si algo era guay o no en última instancia. Aunque sea anacrónico, suelo asemejar estas redes sociales y su trabajo con el «marketing viral». De hecho, es posible que el marketing viral surgiera de este tipo de entornos, aunque aún se debe investigar al respecto. Este es el nivel en el que la contracultura era especialmente empresarial. Lo que Marwick considera principalmente relaciones comerciales, yo opino que es parte de la estructura de un nuevo hábito. Los grupos sociales crearon sus estilos de vida mediante la aceptación de un conjunto de objetos e ideas que especificaban su posición social (esto no es sólo cierto para los grupos contraculturales sino también para los grupúsculos). Des- de esta perspectiva, los consumidores no eran meros recipientes en los que la industria cultural vertía sus ideas, pero tampoco eran individuos que vivían felices enterrados en un aluvión de bienes que satisfacían totalmente sus necesidades; sino que los productos, producidos por capitalistas (tanto grandes como pequeños), fueron incluidos o excluidos en un ámbito social específico.

Para reforzar la idea de esta economía social mediadora o informal durante la gran aceleración, trataré ahora el caso del consumo ilegal de drogas durante los sesenta. El sexo (Heineman 2011; Herzog 2007; Lau 2000) y la música rock (Poiger 2000; Fenemore 2007; Siegfried 200) han sido ampliamente tratados en otros estudios. La enorme expansión del comercio y el consumo de drogas durante los sesenta estaban íntimamente unidos a cambios en el sexo y el rock. Las drogas también estuvieron profundamente implicadas en materia de política formal, en forma de control de drogas y tratamiento; así como en política informal, en frecuentes y complicadas relaciones entre el radicalismo político y radicalismo psíquico. $\mathrm{Y}$ en estos puntos de convergencia, donde lo material y comercial confluyen con lo ideológico y conductual, es donde los «estilos de vi-

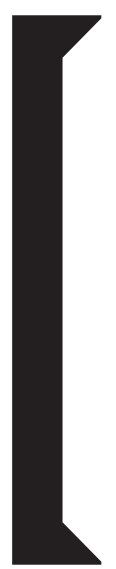

Un "consumismo de moda, una especie de máquina cultural en constante movimiento

en la que la indignación, quejunto con la falsedad, la baja calidad y las opresiones cotidianas de la sociedad consumista, pudieran ser usadas para conducir las cada vez más aceleradas ruedas del consumo".

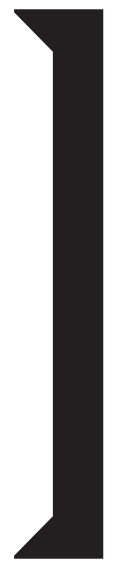

da» fueron creados y refutados. Para ilustrar la compleja relación entre lo material y lo ideológico en esta economía social informal necesito trazar brevemente las transformaciones sociales que permitieron esta nueva economía, las transformaciones ideológicas que acompañaron este cambio y el «declive» del «estilo de vida» contracultural.

Una pieza clave para el aumento del consumo de drogas recreativas por parte de los jóvenes fue la mejora generalizada del nivel de vida en Alemania y el mundo industrializado en general durante los años cincuenta y principios de los sesenta. En el transcurso de una década, el gasto de los consumidores se expandió hasta cifras sin precedentes. Mientras que la primera parte del «milagro económico» se había basado en gran medida en la represión por parte del gobierno de la demanda del consumidor y el fomento de las exportaciones, en 1958 los largamente oprimidos alemanes occidentales empezaron a consumir de una manera inusitada y, en opinión de las autoridades, a veces alarmante (Wildt 1996). Cuando se desató el deseo del consumidor, la primera gran ola de consumismo se cen- 
tró en los llamados Genussmittel, productos estimulantes como los cigarrillos, el alcohol o los bombones. Esto también incluía las tecnologías que eran del gusto de los jóvenes como los cómics, las radios y los tocadiscos. Durante los sesenta, este centro de atención en los Genussmittel se transformó para muchos en un interés en otras economías libidinales, que incluían no solo el aumento de la popularidad de algunas drogas, sino también la llamada revolución sexual. Para situar este proceso en una línea del tiempo en Alemania Occidental, los precursores habían empezado a experimentar con drogas a finales de los cincuenta. En 1964, los derivados del cannabis (incluyendo la marihuana y el hachís), estaban ampliamente aceptados en una "contracultura» emergente que se desarrolló en torno a las universidades. Este pequeño círculo, avivado por el creciente uso del cannabis y la aparición de los psicodélicos, se expandió rápidamente a finales de los sesenta y alcanzó su punto álgido en 1970, cuando los diques del decoro se derrumbaron y las drogas inundaron los institutos de Alemania. El comienzo de los setenta marcó la cota máxima para cualquier tipo de noción liberadora del consumo de drogas. La riada de heroína hacia Alemania después de 1972 estaba vinculada con la agitación económica desencadenada por la Crisis del Petróleo de 1973, y el aumento del terrorismo de izquierdas marcó el final de la época dorada de la contracultura psicodélica (Stephens 2007; Morris 2009). El «juicio comedido», por usar un término de Marwick, mostrado por las autoridades a finales de los sesenta y principios de los setenta desapareció, y la represión del consumo y distribución de drogas, al igual que el terrorismo, se convirtió en la máxima prioridad del estado de Alemania Ocidental (Morris 2009: 181231). La economía informal de la gente joven vendiéndose bolsas de hachís o LSD unos a otros, que había dominado los sesenta, quebró debido a la presión de los mercados organizados y la represión policial. ${ }^{3}$ El idilio psicodélico de Bewusstseinserweiterung dejó paso a la imagen de drogadictos deambulando y agonizando en espacios públicos.

Mientras que el deseo y las nuevas preferencias del consumidor y la cultura popular que respaldaba la expansión de conciencia propiciaban el aumento del consumo de drogas, este fenómeno aparentemente local estaba unido a una política económica global de producción y distribución de droga más grande y cambiante. El aumento de la disponibilidad de estupefacientes, y en especial de productos derivados del cannabis, cocaína y opiáceos, dependía de la creación de nuevas formas de distribución que generaron un mercado global de drogas ilícitas en los años setenta. La Segunda Guerra Mundial alteró la economía ilícita global de la droga que nació de los imperios marítimos del siglo XIX. Durante los años cincuenta se experimentó una considerable disminución en la adicción y el consumo de drogas en Alemania y en la mayor parte de Europa continental. El rápido aumento de la disponibilidad de droga en las calles de Europa durante los sesenta hizo necesaria una nueva red de distribución de drogas ilegales, y dado que los productos derivados del cannabis y los opiáceos (a excepción de los psicodélicos hasta el Convenio sobre Sustancias Psicotrópicas de 1971) estaban controlados por tratados internacionales, este mercado no pudo actuar como los mercados globalizados de productos básicos. En su lugar, la juventud europea y la estadounidense se introdujeron directamente en los mercados que seguían activos en lugares como Marruecos, Turquía, Irán, Afganistán e India (Stephens 2007: 88-120). El mercado de la droga de los sesenta fue impulsado, en gran parte, por este tipo de turismo empresarial. A mediados de los setenta, esta forma de distribución amateur de droga se convirtió en un gran negocio; y la distribución jerárquica mediante el crimen organizado se convirtió en la norma general. Esto quiere decir que las drogas, debido a su estado ilegal, continuaron siendo un mercado particular basado en redes y conocimiento informales, al menos hasta la aparición los mercados de droga abiertos de finales de 1970 (Morris 2009: 181-231; Weinhauer 2006). Este intermediario de economía social informal, motivado bien por su compromiso ideológico, bien por su deseo capitalista, proporcionó a la contracultura parte de su encanto. La carencia de un imperio corporativo de droga, junto con el marketing vinculado a este, las marcas y la publicidad, permitió a los miembros de la contracultura caer en una especie de fetichismo que enmascaró el mercado global de productos básicos que surgía en esos años para apoyar sus deseos de consumidores. Uno podía protestar contra la opresión capitalista del «Tercer Mundo» y disfrutar del hachís del Hindu Kush al mismo tiempo, con pocas disonancias cognitivas.

Estas transformaciones locales y globales en la producción, distribución y consumo fueron de la mano de una serie de transformaciones ideológicas que marcaron las décadas de los sesenta y setenta. Mientras que se ha prestado mucha atención a las ideologías políticas de la Nueva Izquierda en el caso de la Alemania Occidental, la contracultura ha permanecido en un segundo plano. La contracultura era un elemento característico de la izquierda y al menos en Alemania los miembros de la contracultura eran también revolucionarios; mucho más que los hippies de Haight Ashbury. ${ }^{4} \mathrm{~A}$ principios y mediados 
de los sesenta floreció la contracultura de varias clases, promovida por el speed al principio y por el hachís después. Esta incipiente cultura underground fue el campo de pruebas de los Beatles durante su estancia en Hamburgo, hecho que llevó al desarrollo de una importante literatura vanguardista como $\mathrm{Hu}$ bert Fichte, Bernward Vesper y Rolf Dieter Brinkmann (Ingliss 2012; Leigh 2011; Fichte 2005; Vesper 1983; Brinkmann, 1969). La aparición de la cultura underground llegó a un punto de inflexión en 1964; y la segunda mitad de la década se ha conocido desde entonces como la era Flower Power. El consumo de cannabis se extendió rápidamente y los psicodélicos entraron en juego, dándole a los sesenta ese estilo tan peculiar. La ideología hippie o contracultural fue importada en gran medida de los Estados Unidos, pero adquirió un carácter propio en la Alemania Occidental, que empezaba a girar alrededor de la política radical de esa época. Esta interacción entre cultura y comercio, entre fumar hierba y crear música, entre el rechazo a la autoridad y escribir sobre la revolución se produjo en una economía social informal. Y el tomar parte en los rituales de la contracultura, a menudo de una naturaleza deliberada e intensamente local, confirió credibilidad a la idea de que este era un camino para distanciarse (aussteigen) de una cultura del consumismo corrupta y frustrante de la época de la Guerra Fría. Aun así, el objetivo no era colocarse o tener sexo, sino crear un nuevo mundo; aunque formulado de forma imprecisa.

El conflicto entre la contracultura y la Nueva Izquierda organizada creció en el transcurso de los sesenta. La relación entre los dos grupos fracasó en las nociones ideológicas particulares de la revolución. Mientras que la Nueva Izquierda, representada en mayor parte por los maoístas y los K-Gruppen, avanzó hacia una posición revolucionaria explícita a partir de 1968, la contracultura siguió insistiendo en la idea de que la revolución no requería una vanguardia violenta ni una larga marcha a través de las instituciones, sino una transformación de la conciencia y de la vida privada. Esto no impidió que miembros de un grupo se incluyeran más tarde en otros. De hecho, muchos integrantes de los que terminarían siendo grupos terroristas comenzaron en la contracultura, incluyendo a Andreas Baader, de la Fracción del Ejército Rojo, y a Bommi Baumann, del Movimiento 2 de Junio (Koenen 2003; Baumann 2002). La Nueva Izquierda insistía, a finales de los sesenta, en que las drogas eran una parte inherente de la contrarrevolución. Esta división en los modos de pensar se hizo más obvia en 1972 durante un Congreso Anti-Droga patrocinado por Klaus Ranier Röhl, editor de la revista Konkret. Todo este asunto derivó en recriminaciones mutuas y malentendidos (Stephens 2007: 207-210), pero todavía quedaban lazos de unión entre el submundo de la droga y la política en los setenta. "Los consumidores de heroína y los okupas surgieron del mismo entorno de los años setenta, con afiliaciones parecidas y el mismo ímpetu de alterar la sociedad de la Alemania Occidental», afirma Will Morris. «El radicalismo fue la contraseña de ambos grupos» (2009: 130). Este radicalismo compartido, sin embargo, solo tuvo restos del idealismo de la época Flower Power; la paz, el amor y la comprensión tornaron hacia una actitud más militante. Al mismo tiempo que John Lennon nos pedía que imaginásemos a «toda la gente compartiendo el mundo» (en su canción Imagine, «all the people sharing all the world»), el carácter de la transformación individual que la contracultura había consolidado dio paso al faccionalismo, a la decepción y a la desintegración.

Durante los setenta, los antiguos miembros de la contracultura empezaron a cambiar sus intereses: formaron familias, se afiliaron a Los Verdes y fundaron movimientos alternativos. La economía informal que había permitido el florecimiento de la contracultura o bien se asimiló o colapsó. Mientras que, para historiadores como Marwick, esta facción de la izquierda fue tanto inevitable como positiva, para los miembros de la contracultura este hecho supuso una decepción. Cuando los hippies de los sesenta empezaron a vivir otra etapa de su vida, muchos de ellos siguieron pensando que se había desaprovechado una oportunidad. La economía social informal específica que habían intentado crear una especie de capitalismo más generoso y humilde sobrevivió en algunas formas: las centrales y distribuidoras no cerraron porque el Verano del Amor (Summer of Love) hubiese llegado a su fin, pero el tipo de capitalismo inspirado en el modelo estadounidense que dominó

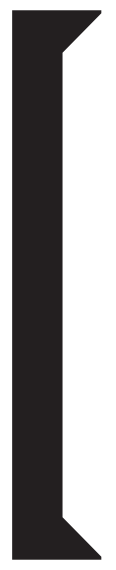

En el transcurso de los “largos años sesenta”,
como resultado de la Gran Aceleración,
una visión especificica del mundo se basó
en la victoria del consumidor capitalista,
hecho que se consolidó con el colapso
de la Unión Soviética. Estoy de acuerdo
con Marwick en ese sentido

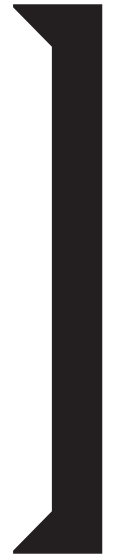

el periodo de la posguerra continuó expandiéndose a un ritmo constante y absorbió muchas de las innovaciones de la contracultura para su maquinaria perpetua de marketing.

La tesis de la revolución cultural es, en esencia, una discusión sobre la transformación y la periodización culturales. Para Marwick, la revolución cultural tuvo lugar durante unos «largos sesenta» que duraron desde 1958 hasta 1974, caracterizados por un cambio hacia el consumidor contemporáneo y la democracia liberal. Para Gerd Koenen, sin embargo, su revolución cultural, basada en la política radical, no comenzó hasta 1967, y duró hasta el Otoño Alemán de 1977. El poder de ambas versiones la liberal y la radical reside en la habilidad de situar el fervor radical y la retórica revolucionaria del periodo anterior a ellas. Para Marwick, lo que quedó después es el triunfo de mentes más serenas, la caída del Comunismo que cambió la visión de la democracia liberal y el mundo brillante en el que vivimos ahora. Para Koenen, la historia es menos triunfal: hay melancolía por el fracaso de transformar el mundo y un orgullo desencantado, pues la Revolución Cultural del 
68 ha mantenido un interés notable por las cosas que realmente importan (2001: 498-500). Ambas versiones se basan en una mirada hacia atrás nostálgica, cosa que no nos sorprende dada la afiliación generacional de los dos autores. La pregunta sigue siendo, no obstante, ¿cómo podemos nosotros, la generación que nació después de estos días turbulentos, examinar sobriamente esa época tóxica? ¿Cómo podemos evitar que los Escila y Caribdis del liberalismo se conviertan en un mito? ¿Cómo darle sentido a la contracultura de los sesenta y los setenta en sus propios términos? Mi respuesta es engañosamente sencilla: tenemos que renunciar a las historias de aquellos que ven los sesenta como un periodo fácilmente anulable. La verdad es que ya se vea de forma negativa o positiva su revolución cultural nunca sucedió. Simplemente fue la Gran Aceleración durante la que el capitalismo se las ingenió para expandirse de una forma tan sustancial que la disidencia era una opción real y fácil de llevar a cabo.
Así pues, déjenme concluir volviendo a la perspectiva de John Lennon. Lennon, en cierto sentido, tenía razón: la contracultura (y por qué no decirlo, los comunistas) estaba preparada, pero los viejos canallas de siempre lo controlaban todo. Y que Marwick se muestre satisfecho con ese resultado y Koenen se muestre nostálgico me deja con una gran sensación de arrepentimiento. En el transcurso de los «largos años sesenta», como resultado de la Gran Aceleración, una visión específica del mundo se basó en la victoria del consumidor capitalista, hecho que se consolidó con el colapso de la Unión Soviética. Estoy de acuerdo con Marwick en ese sentido. Pero, a altas horas de la noche, aún espero que algún día decidamos prepararnos de nuevo y que nos permitamos tener pensamientos utópicos otra vez. La década de los sesenta y la contracultura tienen valor en la medida en que nos ofrecen un recordatorio de que el presente no es el único resultado posible y de que todos, juntos, todavía podemos cambiar nuestro futuro colectivo.

\section{Bibliografía}

Baumann, Bommi (2002), How it all began: the personal account of a West German guerilla. Arsenal Pulp Press.

Brinkmann, Rolf Dieter (Hg.) (1969), Acid : neue amerikanische Szene. März Verlag.

Bourdieu, Pierre (1984), Distinction: A Social Critique of the Judgement of Taste. Harvard University Press.

Chaney, David (2012), Lifestyles. Routledge.

Cohen, Lizabeth (2008), A Consumers' Republic: The Politics of Mass Consumption in Postwar America. Random House.

Collier, Peter, \& Horowitz, David (2005), Destructive Generation: Second Thoughts About The Sixties. Encounter Books.

Cook, Deborah (1996), The Culture Industry Revisited: Theodor W. Adorno on Mass Culture. Rowman \& Littlefield.

Crew, David F. (Ed.) (2003), Consuming Germany in the Cold War. Berg.

Fenemore, Mark (2009), Sex, Thugs and Rock «n» Roll: Teenage Rebels in Cold-War East Germany. Berghahn Books

Fichte, Hubert (2005), Die Palette. Roman. FischerTaschenbuch-Verlag.

Fine, William, \& Love, Nancy (1999), Fighting for the Sixties: Political Movements and Cultural Change.» Polity, 32(2), 285-299. doi: $10.2307 / 3235287$

Fink, Carol, Gassert, Phillip, \& Junker, Detlef (Hg.) (1998): 1968: The World Transformed. Cambridge University Press.

Frank, Thomas (1998), The Conquest of Cool: Business Culture, Counterculture, and the Rise of Hip Consumerism. University of Chicago Press.

Gassert, Phillip, \& Klimke, Martin (Hg.) (2009), 1968: memories and legacies of a global revolt. German Historical Institute.

Grazia, Victoria de (2005), Irresistible Empire. Harvard University Press.

Hebdige, Dick (2012), Subculture: The Meaning of Style. Routledge.

Heineman, Elisabeth (2011), Before Porn Was Legal: The Erotica Empire of Beate Uhse. University of Chicago Press.

Heineman, Elisabeth (2006), The Economic Miracle in the Bedroom: Big Business and Sexual Consumption in Reconstruction West Germany, The Journal of Modern History, 78(4), 846877. doi:10.1086/511204

Herzog, Dagmar (2005), Sex After Fascism: Memory And Morality In Twentieth-century Germany. Princeton University Press.

Hobsbawm, Eric (2001), The Age of Extremes: A
History of the World, 1914-1991. Peter Smith. Inglis, Ian (2012), The Beatles in Hamburg. Reaktion Books.

Jarausch, Konrad (2006), After Hitler: Recivilizing Germans, 1945-1995. Oxford University Press.

Jarausch, Konrad, \& Geyer, Martin (2009), Shattered Past: Reconstructing German Histories. Princeton University Press.

Koenen, Gerd (2001), Das Rote Jahrzehnt: Unsere Kleine Deutsche Kulturrevolution, 1967 1977. Kiepenheuer \& Witsch.

Koenen, Gerd (2005), Vesper, Ensslin, Baader: Urszenen des deutschen Terrorismus. Fischer Taschenbuch.

Lau, Mariam (2000), Sexfronten: Das Schicksal einer Revolution. Fest.

Leigh, Spencer (2012), The Beatles in Hamburg: The Stories, the Scene and How It All Began. Omnibus Press.

Lüdtke, Alf (Ed.) (1995), The History of Everyday Life: Reconstructing Historical Experiences and Ways of Life. Princeton University Press.

Marwick, Arthur (1998), The sixties: cultural revolution in Britain, France, Italy, and the United States, c.1958-c.1974. Oxford University Press.

Morris, William F. (2009), Opening German minds| Drug users, social tolerance, and the making of West Germany, 1967-1983 (Doctoral dissertation, University of Illinois at Urbana-Champaign).

Passerini, Luisa (1999), Reseña del libro The Sixties: Cultural Revolution in Britain, France, Italy, and the United States, c. 1958-c. 1974, de Arthur Marwick, American Historical Review $104,1642$.

Poiger, Uta (2000), Jazz, Rock, and Rebels: Cold War Politics and American Culture in a Divided Germany. University of California Press.

Renner, Jens (2001), 1968. Rotbuch Verlag.

Richthofen, Esther von (2009), Bringing Culture to the Masses: Control, Compromise and Participation in the GDR. Berghahn Books.

Rossinow, Doug (1998), The Politics of Authenticity: Liberalism, Christianity, and the New Left in America. Columbia University Press.

Schildt, Axel, \& Siegfried, Detlef (Hg.) (2006), Between Marx and Coca-Cola: Youth Cultures in Changing European Societies, 1960-1980. Berghahn Books.

Siegfried, Detlef (2006), Time is on My Side: Konsum und Politik in der westdeutschen Jugendkultur der 60er Jahre. Wallstein Verlag.

Stephens, Robert P. (2007), Germans on Drugs: The Complications of Modernization in Hamburg. University of Michigan Press.

Strasser, Susan, McGovern, Charles, \& Judt, Mat- thias (Ed.) (1998): Getting and Spending: European and American Consumer Societies in the Twentieth Century. Cambridge University Press. Susman, Warren (1984), Culture as History: The Transformation of American Society in the Twentieth Century. Pantheon Books.

Swett, Pamela E., Wiesen, S. Jonathan, \& Zatlin, Jonathan R. (Ed.) (2007), Selling Modernity: Advertising in Twentieth-Century Germany. Duke University Press.

Vesper, Bernward (1983), Die Reise. Romanessay. Rowohlt.

Weinhauer, Klaus (2006), Drug Consumption in London and Western Berlin During the 1960s and 1970s: Local and Transnational Perspectives, en Social History of Alcohol and Drugs, 20(2), 187-224.

Wesel, Uwe (2002), Die verspielte Revolution: 1968 und die Folgen. Blessing.

Wildt, Michael (1996), Vom kleinen Wohlstand. Eine Konsumgeschichte der fünfziger Jahre. Fischer.

Willis, Ellen (1998, November 8), Reseña del libro The Sixties: Cultural Revolution in Britain, France, Italy, and the United States, c. 1958-c. 1974, de Arthur Marwick, New York Times.

1 Traducción del inglés de Melani Infante Becerra, Raquel Silva León y Maria Eugenia Gómez Rejano (Universidad Pablo de Olavide).

2 Para este tipo de crítica conservadora, consultar Collier y Horowitz, 1996 [nota del editor].

3 Quisiera señalar que veo una diferencia real y sustancial entre las economías informales y las sumergidas. Las primeras suelen ser a pequeña escala y de naturaleza irregular, mientras que las economías sumergidas, a las que me refiero como economías ilícitas, se dan a gran escala. No quiero decir con esto que haya economías informales "buenas» y economías sumergidas «malas». Ambas son economías capitalistas, la única diferencia es la dimensión. No obstante, hay una diferencia real cualitativa y cuantitativa entre un estudiante de instituto vendiendo un porro y el Cartel de Medellín. Esto puede parecernos obvio, pero es demasiado fácil encasillar las dos en economías ilícitas. Las consecuencias de la incapacidad para diferenciarlas puede verse reflejada en la política estadounidense desde mediados de los ochenta.

4 Barrio de San Francisco, sede del movimiento beatnik a finales de los cincuenta. 